\title{
Adaptive Neuro Fuzzy Interface System Based Short Circuit Fault Diagnoses in a Three Phase Induction Motor Drive System
}

\author{
Khaled A. Mahafzah*, Hossam Fraihat \\ Faculty of Engineering, Al Ahliyya Amman University, Amman, Jordan \\ Received April 6, 2021; Revised May 11, 2021; Accepted May 28, 2021
}

\section{Cite This Paper in the following Citation Styles}

(a): [1] Khaled A. Mahafzah, Hossam Fraihat, "Adaptive Neuro Fuzzy Interface System Based Short Circuit Fault Diagnoses in a Three Phase Induction Motor Drive System, "Universal Journal of Electrical and Electronic Engineering, Vol. 8, No. 2, pp. 35 - 40, 2021. DOI: 10.13189/ujeee.2021.080202.

(b): Khaled A. Mahafzah, Hossam Fraihat (2021). Adaptive Neuro Fuzzy Interface System Based Short Circuit Fault Diagnoses in a Three Phase Induction Motor Drive System. Universal Journal of Electrical and Electronic Engineering, 8(2), 35 - 40. DOI: 10.13189/ujeee.2021.080202.

Copyright $\bigcirc 2021$ by authors, all rights reserved. Authors agree that this article remains permanently open access under the terms of the Creative Commons Attribution License 4.0 International License

\begin{abstract}
Induction motors are commonly used in different industrial, housing and medical applications, such as air conditioners, transportation, elevators and others. These motors are rugged, reliable and economical. Generally, the reliable operation of the motor and its drive system is very important in industry so that any expected fault must be detected immediately by a monitoring system. This paper reviews and simulates a three-phase induction motor model and different types of faults that may happen in the drive system. Due to short circuit severity on the overall drive system, this study focuses only on short circuit faults, e.g., when any Insulated Gate Bipolar Transistor (IGBT) is shorted out and DC link capacitor is shorted out. Also, an Adaptive Neuro Fuzzy Interface System (ANFIS) algorithm is programmed to detect different types of faults and classify them. The ANFIS system takes two parameters as input from the motor: the first one is the load torque whereas the second one is the stator current. Whereas, the previously published works analyze only the motor's stator current. MATLAB is used to train the ANFIS system and also to analyze samples. Additionally, LTSpice is used simulate the drive system. The ANFIS system shows very high accuracy in short circuit fault detection and classification.
\end{abstract}

Keywords Drive System, Short Circuit, Fault Detection, Adaptive Neuro Fuzzy Inference System (ANFIS)

\section{Introduction}

The popularity of Induction Motors (IM) comes from their robustness, variable speed operation, efficient and low maintenance cost. Adjustable Speed Drives (ASDs) are commonly used to drive such motors and for variable speed operation, Figure 1 [1]. During the IM operation, different types of failure may happen. Some are happened at the motor side e.g., mechanical such as bearing faults and eccentricity faults and others are electrical faults. The electrical failure may hit the motor sides or it's driving system [2-5].

To maintain the reliability operation of the IM, the driving system must be protected against any failure. As seen in Figure 1, the system is divided into: a Diode Bridge Rectifier (DBR) followed by an inverter linked to each other by a DC coupling capacitor. Many types of faults occur at the driving side of the motor and can be summarized as [6-7]:

1. Faults occur on the Diode Bridge Rectifier side (a diode is opened or shorted out).

2. Faults occur on the DC link capacitor (DC capacitor is opened or shorted out).

3. Faults occur on the inverter side (a switch is opened/ shorted out or loss the gating signals). 


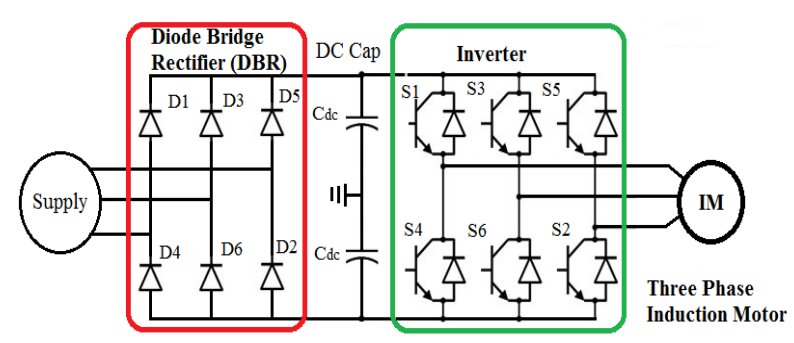

Figure 1. IM's Drive system

However, failure diagnosis in the driving system is required, so in one hand many techniques are proposed and used to detect any failure in the driving system. Some researches focus on the fault detection. They introduce different techniques to detect the fault such as employing Rogowski sensor [7], despite of eliminating the need of an integrator in the current acquisition system but using this technique needs precise filter attenuation for accurate fault detection. The failure of the current sensor in the driving system is introduced in [8]. Thus, a Fault Detection and Isolation unit (FDI) is designed which adds more complexity in the system.

A Motor Current Signature Analysis (MCSA) is proposed in [9]. This technique is used to detect both mechanical and electrical faults may occur in the system. The proposed method needs an open loop variable frequency control.

A Model Predictive Control (MPC) is employed in [10] to detect the fault in the driving inverter but for multi-phase IM (Five Phases). Both Open Phase Fault (OPF) and Open Switch Fault (OSF) are detected by this strategy. Paper [11] bales to detect the fault in the driving system by proposing a new approach called Multiple Windowed Harmonic Wavelet Packet Transform (MWHWPT). This approach is designed to suit with the varying current spectral content.

The traditional methods of fault detection in the driving system do not give adequate results. So, researchers employ an artificial intelligence method for this issue. E.g., in [12], A hybrid system (based on vibrations and current sensors) is designed employing fuzzy logic to diagnoses the fault types hit the motor itself. Additionally, [13], designed a fuzzy logic system to detect the fault that may occur on the induction motor side. Authors in [14] designed a fuzzy logic system to detect the fault occurs in the driving system. The designed fuzzy logic system uses the measured stator current of the motor. The reason is to detect the discontinuity in the controlled pulses of power switches.

All aforementioned references design a fuzzy logic system at a specific operation point (torque) of the induction motor, leaving an important question open behind them: is it possible to design a fuzzy logic to detect and classify driving system fault precisely if the motor's torque changes side by side with its stator current?

This paper designs a fuzzy logic system to detect and classify a fault occurs in three phase IM driving system. The algorithm receives motor's stator currents and load torque, simultaneously. Based on the measured RMS stator current and the load torque, the fuzzy system decides whether the motor is healthy or not. Moreover, it tells the type of the fault that attacks the driving system with a high precision. Also, the designed fuzzy system is tested on only two kinds of faults as case study. First, when DC bus capacitors are shorted out. Second; when the power switch is shorted out. This is because of the severity of these fault types. Occurring such faults will increase the current in the circuit, thus, increasing the thermal stress on the power circuit.

Also, in this paper an Adaptive Neuro Fuzzy Inference System (ANFIS) is designed to detect and classify a short circuit fault may hit the DC capacitor or IGBTs of the inverter. The result of the detection process shows 100\% accuracy when an IGBT is shorted out and 96\% accuracy when detecting a short circuit DC capacitor fault and healthy Induction Motor.

The paper discusses the induction motor model, control of driving system and the simulation waveforms in Section 2. Section 3 discusses the ANFIS design and classification method. Last but not least, the conclusions of this paper are drawn in Section 4.

\section{Induction Motor: Model, Control and Simulation}

\subsection{Krause's Model}

Each part of the motor (stator or rotor) does have its own equations. A set of differential equations describe the induction motor is called Krause's model [15]. According to this model the differential equations are described as follow (starting from flux linkage equations):

$$
\begin{gathered}
\frac{d F_{d s}}{d t}=\omega_{b}\left(V_{d s}+\frac{\omega_{e}}{\omega_{b}} F_{q s}-\frac{R_{s}}{x_{l s}}\left(F_{m d}-F_{d s}\right)\right) \\
\frac{d F_{q r}}{d t}=\omega_{b}\left(V_{q r}-\frac{\left(\omega_{e}-\omega_{r}\right)}{\omega_{b}} F_{d r}-\frac{R_{r}}{x_{l r}}\left(F_{m q}-F_{q r}\right)\right) \\
\frac{d F_{d r}}{d t}=\omega_{b}\left(V_{d r}+\frac{\left(\omega_{e}-\omega_{r}\right)}{\omega_{b}} F_{q r}-\frac{R_{r}}{x_{l r}}\left(F_{m d}-F_{d r}\right)\right)
\end{gathered}
$$

The Components of Magnetizing Flux are given by:

$$
\begin{aligned}
& F_{m q}=x_{m l}^{*}\left(\frac{F_{q s}}{x_{l s}}+\frac{F_{q r}}{x_{l r}}\right) \\
& F_{m d}=x_{m l}^{*}\left(\frac{F_{d s}}{x_{l s}}+\frac{F_{d r}}{x_{l r}}\right)
\end{aligned}
$$

The machine stator current is described by the following equations:

$$
\begin{gathered}
i_{q s}=\frac{\left(F_{q s}-F_{m q}\right)}{x l s} \\
i_{d s}=\frac{\left(F_{d s}-F_{m d}\right)}{x_{l s}}
\end{gathered}
$$

The machine rotor current is described by the following 
equations:

$$
\begin{gathered}
i_{q r}=\frac{\left(F_{q r}-F_{m q}\right)}{x_{l r}} \\
i_{d r}=\frac{\left(F_{d r}-F_{m d}\right)}{x_{l r}}
\end{gathered}
$$

The electromagnetic torque on the machine shaft can be expressed as:

$$
\begin{gathered}
T_{e}=\frac{3 P}{4 \omega_{b}}\left(F_{d s} i_{q s}-F_{q s} i_{d s}\right) \\
T_{e}-T_{L}=J \frac{2}{P} \frac{d \omega_{r}}{d t}
\end{gathered}
$$

The rotor speed of the shaft can be expressed as:

$$
\omega_{r}(t)=\frac{P}{2 J} \int\left(T_{e}-T_{L}\right) d t
$$

\subsection{Drive System Control}

Many ways are used to generate proper pulses for three-phrase inverters. The most common two ways are Sinusoidal Pulse Width Modulation (SPWM) and Space Vector Pulse Width Modulation (SVPWM) [16]. In A SPWM, a three sinusoidal waveforms reference signals) shifted by 120 degree off each other are compared with a triangular waveform (carrier signal). When the sine wave is greater than the triangle then the phase related upper switch is turned on and vise-versa for the phase related lower switch [17]. The other method is called Space Vector Pulse Width Modulation technique (SVPWM). The only main difference in these two methods is the total harmonics contents in the output voltage. However, the SVPWM has lower harmonics contents in the output voltage compared with the SPWM. But, it is a bit complicated to implement [16-17]. (See Appendix A).

\subsection{Induction Motor Simulation}

A three-phase voltage source with RMS line voltage was $400 \mathrm{~V}$ connected to rectifier, with two $100 \mathrm{uF}$ DC capacitors. The inverter switches are selected as IGBTs with an external free-wheeling diode, the switching frequency of the inverter is $200 \mathrm{kHz}$. A Sinusoidal Pulse Width Modulation method is simulated using MATLAB/SIMULINK.

A $3 \mathrm{Hp}$, three phase squirrel-cage induction motor with rated phase voltage $230 \mathrm{~V}$, rated speed $180 \mathrm{RPM}$, it has two pairs pole, with stator winding resistor rotor resistors are 0.435 and $0.816 \mathrm{ohm}$, respectively. The stator leakage and rotor leakage inductances are $4 \mathrm{mH}$ and $2 \mathrm{mH}$ respectively, and finally the moment of inertia $\mathbf{J}$ is 0.089 $\mathrm{kgm}^{2}$.

To simulate the fault, it is possible to connect an ideal switch in parallel with the component to introduce the short circuit fault. Also, the fault should happen after steady state operation of the motor, otherwise it will detect the starting current of the motor as a fault, for this reason it is important to determine the steady state time. So, the fault will be introduced after few milliseconds of running the simulation.
Because of symmetrical three phase operation of induction motor, the results show single phase stator current as shown in Figure 2. Also, the fault is applied to single device in the induction motor drive system. Moreover, the results introduce and discuss only two faults types that may occur on the driving system such as DC link capacitor is shorted out and the other one is when IGBT is shorted out.

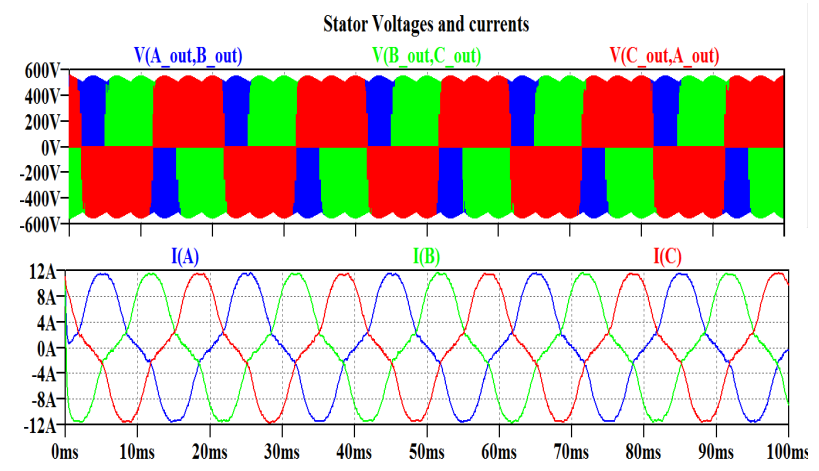

Figure 2. A three phase stator voltages (top) and currents (bottom) of healthy IM

Figure 3 shows the stator current (phase A) when the DC bus is shorted out. At $0.3 \mathrm{sec}$, the stator current suddenly increases to a high value then it decreases to very low value compared to the normal operation current. The reason for this decreasing is due to decreasing in the DC voltage across the DC link capacitors. Figure 4, shows the stator current when IGBT1 is shorted out. Clearly, the stator current will dramatically increase, it may reach 180 A, actually, this increasing has dangerous on the power circuit. In one hand, the drive system will be damaged due to very high current stress on the switches. On the other hand, the circulating current in the motor windings produces an excessive thermal stress and the temperature of the motor will highly increase in a very short time. Hence, this will directly affect the windings insulation and causes to break down of this insulation.

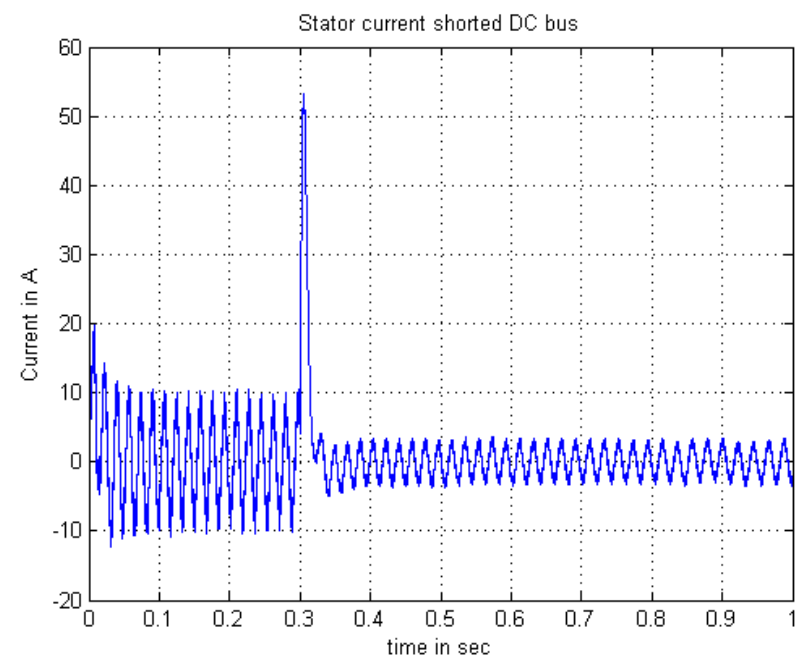

Figure 3. Measured stator current. DC link capacitor short circuit fault 


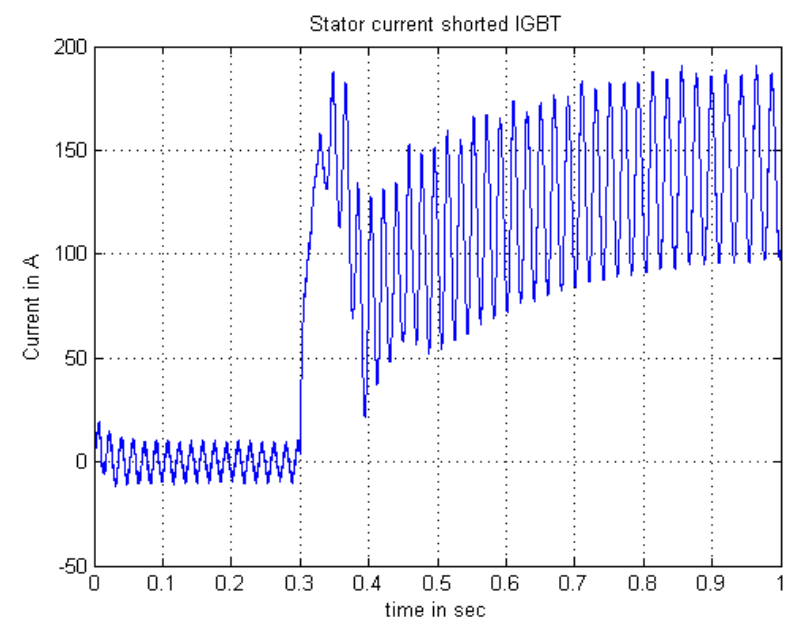

Figure 4. Measured stator current. IGBT switch short circuit fault

\section{Fault Diagnosis and Classification by ANFIS Classifier}

ANFIS is a revealing artificial intelligence technique for data classification. The ANFIS architecture depends on five layers of nodes. They are integrated to compare the input signal against prior knowledge stored. Two layers of ANFIS are adaptive and the rest are consisting of fixed nodes [18 - 20]. The Inputs of the ANFIS are: the load torque and stator current of IM. The outputs of ANFIS classifiers are: (i) Class 1 (blue color) indicates Healthy Induction Motor (HIM). (ii) Class 2 (red color) indicates Faulty Driving System (DC bus is shorted out), and (iii) Class 3 (green color) indicates Faulty Driving System (IGBT is shorted out). The training parameters of ANFIS are given in Table 1.

Table 1. Internal ANFIS parameters for best classification

\begin{tabular}{|c|c|}
\hline Type & SUGENO \\
\hline andMethod & Prod: \\
\hline orMethod & Probor \\
\hline Defuzzification Method & $\begin{array}{c}\text { Wtaver (Weighted avera } \\
\text { berfomance.ge of all rule outputs) }\end{array}$ \\
\hline Implication Method & Prod \\
\hline Aggregation Method & Sum \\
\hline Input & 2 \\
\hline Output & 1 \\
\hline Rules & 12 \\
\hline Epoch & 200 \\
\hline ranges of influence & 0.3 \\
\hline
\end{tabular}

The PRECISION, RECALL and F-SCORE statistical metrics are calculated using (13), (14) and (15), respectively:

$$
\begin{array}{r}
\text { Precision }=\frac{T P}{(T P+F P)} \\
\text { RECALL }=\frac{T P}{(T P+F N)}
\end{array}
$$

$$
F-\text { score }=\frac{2 * \text { precision } * \text { RECALL }}{(\text { precision }+R E C A L L)}
$$

\section{Results and Discussion}

The proposed approach employs Adaptive Neuro Fuzzy Inference System (ANFIS). Figure 5 shows the ANFIS's outputs for 576 test samples for phase A. All class 3 samples are successfully detected, while only one sample from class 1 is not detected truly, but it is detected as class 2, which is false. Eleven samples from class 2 are detected as class 1 and they are considered as class 1 which is false. Each class in the dataset containing 2880 samples was randomly categorized as training 80\% (2304 samples) and testing sets $20 \%$ (576 samples), as shown in Table 2. The ANFIS is trained for the whole dataset. The ANFIS outcomes are observed. The precision, recall and accuracy are reported. Table 2 shows the overall results of the framework for each class. Although class 1, class 2 and class 3 have different value of current, the ANFIS achieved close values of accuracy detection $96 \%$ for class $1,96 \%$ for class 2 and $100 \%$ for class 3 .

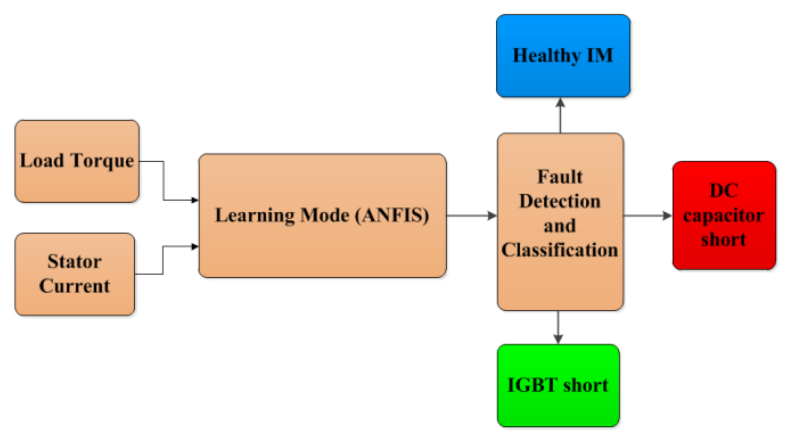

Figure 5. ANFIS classifier work flow

Table 2. The framework performance on dataset

\begin{tabular}{|c|c|c|c|}
\hline Class & PRECISION & RECALL & F-SCORE \\
\hline Class 1 & 0.937853107 & 0.994011976 & 0.9651162 \\
\hline Class 2 & 0.994818652 & 0.945812807 & 0.9696969 \\
\hline Class 3 & 1 & 1 & 1 \\
\hline
\end{tabular}

Classe1:HIM Classe2:DC Classe3:IGBT

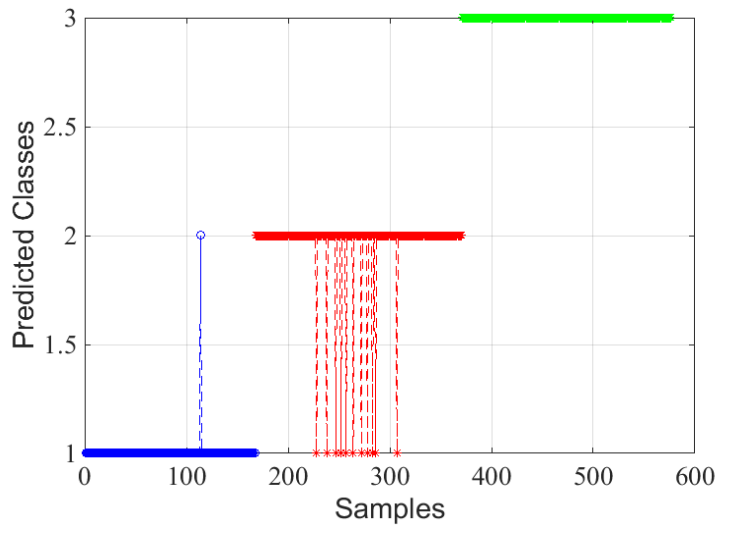

Figure 6. The designed ANFIS outputs test samples. 


\section{Conclusions}

In this paper, short circuit fault detection in IM driving system and classification by Adaptive Neuro Fuzzy Inference System (ANFIS) are proposed. A model of an Induction Motor (IM) is simulated by using MATLAB/simulink.

A Sinusoidal Pulse Width Modulation (SPWM) is used to generate control pulses of the inverter. Short circuit fault across upper IGBT of phase A and short circuit of DC capacitor are applied. ANFIS system receives load torque and stator current of phase A. ANFIS shows a very good accuracy of output classification into different three classes: Healthy IM (Class 1), DC bus short circuit (Class 2) and IGBT short circuit (Class 3). The designed ANFIS shows a $100 \%$ accuracy of IGBT short circuit fault.

\section{Nomenclature}

$\omega_{\mathrm{b}}:$ Base Speed in $\mathrm{rad} / \mathrm{sec}$

$\omega_{\mathrm{e}}$ : Electrical Speed in $\mathrm{rad} / \mathrm{sec}$

$\omega_{\mathrm{r}}:$ Rotor Speed in $\mathrm{rad} / \mathrm{sec}$

$\mathrm{F}_{\mathrm{md}}$ : The direct component of magnetizing flux linkage

$\mathrm{F}_{\mathrm{mq}}$ : The quad component of magnetizing flux linkage

$\mathrm{i}_{\mathrm{d}, \text { ref }}$ : Reference Values in d-axis

$\mathrm{i}_{\mathrm{q}, \mathrm{ref}}$ : Reference Values in q-axis

$\mathrm{i}_{\mathrm{qr}}, \mathrm{i}_{\mathrm{dr}}$ : Rotor Current Components in $\mathrm{q}$ and $\mathrm{d}$ axises

$\mathrm{i}_{\mathrm{qs}}, \mathrm{i}_{\mathrm{ds}}$ : Stator Current Components in $\mathrm{q}$ and $\mathrm{d}$ axises

$\mathrm{J}$ : Moment of Inertia

$\mathrm{P}$ : The number of poles in the motor

$\mathrm{R}_{\mathrm{r}}, \mathrm{X}_{\mathrm{lr}}$ : Rotor Impedance Components

$\mathrm{R}_{\mathrm{s}}, \mathrm{X}_{\mathrm{ls}}$ : Stator Impedance Components

$\mathrm{T}_{\mathrm{e}}$ : Electrical Torque

$\mathrm{T}_{\mathrm{L}}$ : Load Torque

ANFIS: Adaptive Neuro Fuzzy Inference System

FN: False negative represents the abnormal samples detected as normal

FP: False positive represents normal samples detected as abnormal

SPWM: Sinusoidal Pulse Width Modulation

SVPWM: Space Vector Pulse Width Modulation

TN: True negative represents the normal samples detected correctly

\section{Appendix A}

This appendix summarizes the pulse generation steps. Also, compares the SPWM and SVPWM with each other. Figure A.1 illustrates Sinusoidal Pulse Width Modulation. While Figure A.2 presents a Space Vector Pulse Width Modulation.

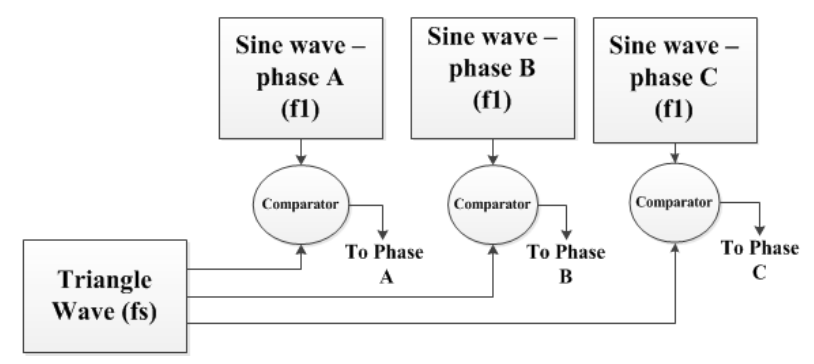

Figure A2. Sinusoidal Pulse Width Modulation (SPWM)

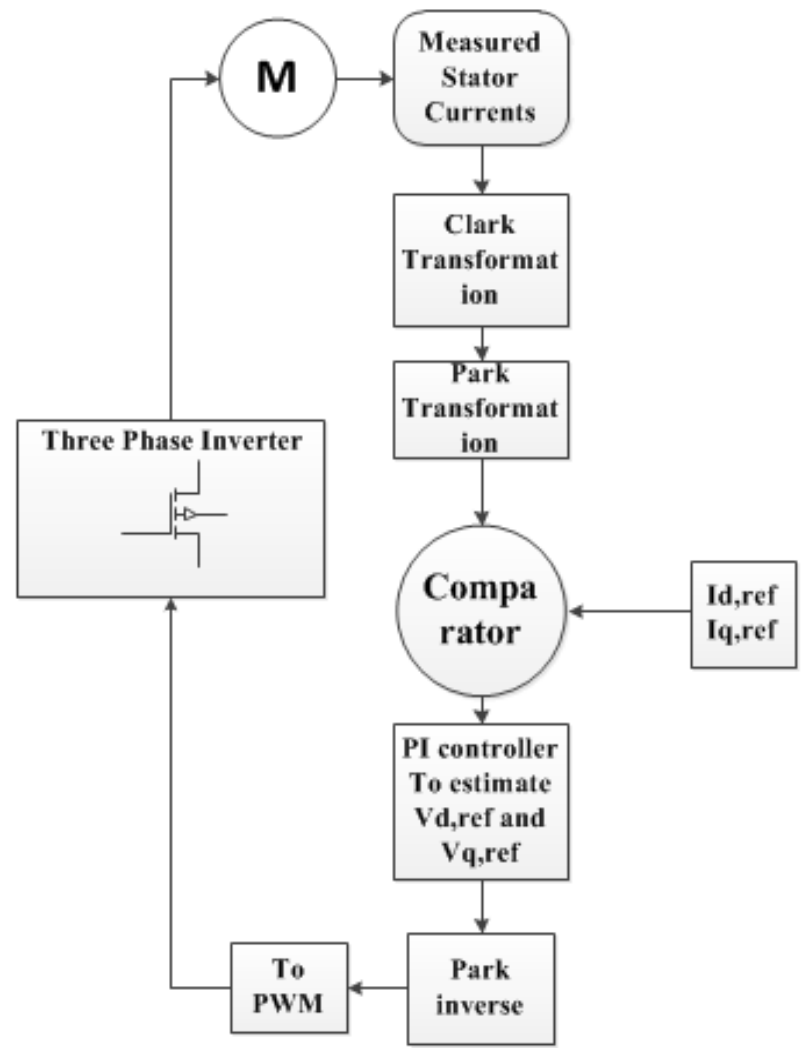

Figure A2. Space Vector Pulse Width Modulation (SVPWM)

\section{REFERENCES}

[1] Reema. N, V.P. Mini and Dr.S. Ushakumari, "Switching fault detection and analysis of induction motor drive system using fuzzy logic," International Conference on Advances in Green Energy (ICAGE), pp. 132-137, 2014, DOI: 10.1109/ICAGE.2014.7050155.

[2] Hassan O.E, Amer M., Abdelsalam A.K and Williams B. W, "Induction motor broken rotor bar fault detection techniques based on fault signature analysis - a review," IET Electric Power Applications, vol. 12, no. 7, pp. 895-907, 2018, DOI: 10.1049/iet-epa.2018.0054. 
[3] Ozpineci B., Tolbert L., "Simulink Implementation of Induction Machine Model- A Modular Approach," IEEE International Electrical Machines and Drives Conference, IEMDC'03, Vol. 2, PP. 728-734, 2003, DOI: 10.1109/IEMDC.2003.1210317.

[4] Alberto L., da Silva Gazzana D. and Pereira L.F, "Motor current Signature Analysis and Fuzzy Logic Applied to the Diagnosis of Short-Circuit Faults in Induction Motor," 31st Annual Conf. of IEEE Industrial Electronics Society, IECON, PP. 275-279, 2005, DOI: 10.1109/IECON.2005.1568916.

[5] Hari Kumar R., Mini V. P. and Mayadevi N., "Fuzzy Intelligent System for Detection of Multiple Switch Open Fault in Induction Motor Drive System," 2019 IEEE 4th Intern. Conf. on Condition Assessment Techniques in Electrical Systems (CATCON), pp. 1-5, 2019, DOI: 10.1109/CATCON47128.2019.CN0003.

[6] Kumar R.S., Raj L. G. C. and Abarna J., "Analysis of Fuzzy Logic Based Fault Detection for Three Phase Induction Motor Drive System," 2018 4th Intern. Conf. on Electrical Energy Systems (ICEES), pp. 700-705, 2018, DOI: 10.1109/ICEES.2018.8443247.

[7] Poncelas O., Rosero J. A., Cusido J., Ortega J. A. and Romeral L., "Motor Fault Detection Using a Rogowski Sensor Without an Integrator," IEEE Trans. on Industrial Electronics, vol. 56, no. 10, pp. 4062-4070, 2009, DOI: 10.1109/ISIE.2008.4677213.

[8] Najafabadi T., Salmasi F. and Maralani P., "Detection and Isolation of Speed, DC-Link Voltage and Current-Sensor Faults Based on an Adaptive Observer in Inducton Motor Drive," IEEE Trans. on Industrial Electronics, Vol.58, No.5, PP.1662-1672, 2011, DOI: 10.1109/TIE.2010.2055775.

[9] Georgakopoulos I. P., Mitronikas E. D. and Safacas A. N., "Detection of Induction Motor Faults in Inverter Drives Using Inverter Input Current Analysis," IEEE Trans. on Industrial Electronics, vol. 58, no. 9, pp. 4365-4373, 2011, DOI: 10.1109/TIE.2010.2093476.

[10] I. González-Prieto, M. J. Duran, N. Rios-Garcia, F. Barrero and C. Martín, "Open-Switch Fault Detection in Five-Phase Induction Motor Drives Using Model Predictive Control," IEEE Trans. on Industrial Electronics, vol. 65, no. 4, pp. 3045-3055, 2018, DOI: 10.1109/TIE.2017.2748052.

[11]Hmida M.A. and Braham A., "Fault Detection of VFD-Fed
Induction Motor Under Transient Conditions Using Harmonic Wavelet Transform," IEEE Trans. on Instrumentation and Measurement, vol. 69, no. 10, pp. 8207-8215, 2020, DOI: 10.1109/TIM.2020.2993107.

[12] Cruz A.G.A., Gomes R.D, Belo F.A. and Lima Filho A.C., "A Hybrid System Based on Fuzzy Logic to Failure Diagnosis in Induction Motors," IEEE LATIN AMERICA TRANSACTIONS, Vol. 15, No. 8, 2017, DOI: 10.1109/TLA.2017.7994796.

[13]Zidani F., Benbouzid M., Diallo D. and Saïd Naït-Saïd M., "Induction Motor Stator Faults Diagnosis by a Current Concordia Pattern-Based Fuzzy Decision System," IEEE Trans. on Energy Conversion, Vol. 18, no. 4, 2003, DOI: 10.1109/TEC.2003.815832.

[14]Zidani F., Diallo D., Benbouzid M. and Saïd Naït-Saïd M. "A Fuzzy-Based Approach for the Diagnosis of Fault Modes in a Voltage-Fed PWM Inverter Induction Motor Drive," IEEE Trans. on Industrial Electronics, Vol. 55, no. 2, 2008, DOI: 10.1109/TIE.2007.911951.

[15] Krause, Paul C., et al. "Analysis of electric machinery and drive systems," Vol. 75. John Wiley and Sons, 2013.

[16] Kumar K. V., Michael P. A., John J. P. and Kumar S. S., "Simulation and Comparison of SPWM and SVPWM Control for Three Phase Inverter," ARPN Journal of Engineering and Applied Sciences, Vol. 5, No. 7, pp: 61-74, 2010.

[17] Türksoy Ö., Y1lmaz Ü., Tan A., Teke A., "A Comparison Study of Sinusoidal PWM and Space Vector PWM Techniques for Voltage Source Inverter," NESciences Journal, Vol. 2, no. 2, PP: 73-84, 2017, DOI: 10.28978/nesciences.330584.

[18] Jyh-shing Roger Jang, Chuen-Tsai Sun, "Neuro-Fuzzy Modeling and Control," Proceedings of the IEEE, Vol. 83, no. 3, 1995, DOI: 10.1109/5.364486.

[19] Jang, J.-S.R., Sun,C.-T., and Mizutani, E, "Neuro-fuzzy and soft computing; a computational approach to learning and machine intelligence," IEEE Trans. on Automatic Control, Vol. 42, no. 10, pp: 1482-1484, 1997.

[20] Jyh-shing Roger Jang, "ANFIS: Adaptive-Network-based Fussy Inference System," IEEE Trans. on Systems, Man, and Cybernetics, Vol: 23, no: 3, 1997, DOI: 10.1109/21.256541. 